\title{
Defending De-idealization in Economic Modeling: A Case Study
}

\author{
Edoardo Peruzzi*1 and Gustavo Cevolani ${ }^{\dagger 2,3}$ \\ ${ }^{1}$ Department of Economics and Statistics, University of Siena, Italy \\ ${ }^{2}$ IMT School for Advanced Studies, Lucca, Italy \\ ${ }^{3}$ Center for Logic, Language, and Cognition, University of Turin, Italy
}

Authors' post-print (accepted author manuscript)
Published in Philosophy of the Social Sciences
(https://doi.org/10.1177/00483931211049759)

\begin{abstract}
This paper defends the viability of de-idealization strategies in economic modeling against recent criticism. De-idealization occurs when an idealized assumption of a theoretical model is replaced with a more realistic one. Recently, some scholars have raised objections against the possibility or fruitfulness of de-idealizing economic models, suggesting that economists do not employ this kind of strategy. We present a detailed case study from the theory of industrial organization, discussing three different models, two of which can be construed as de-idealized versions of the first (the so-called Bertrand model of oligopoly). We conclude that recent pessimism about de-idealization in economics is largely unfounded, and that de-idealization strategies are not only possible but also widely employed in economics.
\end{abstract}

Keywords. Idealization, de-idealization, concretization, economic models, Bertrand model, industrial organization

\section{Introduction}

Theoretical models in science, and in economics in particular, typically contain idealizations of various kinds. While this is widely acknowledged, there

*e.peruzzi@student.unisi.it (Corresponding author)

${ }^{\dagger}$ gustavo.cevolani@imtlucca.it 
is much less consensus about the nature and epistemic role of those idealizations. One important view of idealizations refers to the notion of deidealization (sometimes called "concretization"). According to such view, important episodes of theoretical change in science can be construed as instances of a process that goes from more idealized to more realistic models of phenomena (Nowak 1980; Cools, Hamminga, and Kuipers 1994; Niiniluoto 2002, 2012, 2018; Hindriks 2012).

In recent discussion on the methodology of economics, the notion of deidealization and its role in the practice of the discipline has been strongly criticized (see, in particular, Alexandrova 2008; Alexandrova and Northcott 2009; Reiss 2012). Despite having different views of idealizations and economic modeling, such critics agree on one point: that de-idealization strategies are actually not used in economic modeling, for the good reason that they are either unfeasible or useless. In short, thinking in terms of idealizations and de-idealizations is not a useful or viable approach to understand scientific change and progress, at least as far as theoretical models in economics are concerned.

This paper aims at rebutting this criticism; in particular, we put forward two main claims. First, we argue that the notion of de-idealization is sound and viable as a way of analyzing the relations between different but connected economic models. Second, we show that de-idealization strategies are actually employed by working economists, pointing to a relevant case study concerning the theory of industrial organization. We conclude that the idea of de-idealization provides both a fruitful theoretical perspective on economic modeling, and a way of reconstructing the actual historical development of the discipline.

We proceed as follows. In Section 2, we introduce the strategy of idealizations and de-idealizations, and present some criticism raised against it within recent discussion about economic modeling. In Section 3, we summarize some classical discussion of idealizations and de-idealizations and suggest how this notions can be applied to the case of economic models. To better illustrate our thesis, in Section 4 we present a case study from the theory of industrial organization. More specifically, we discuss three different models of oligopoly markets (the standard Bertrand model, the Bertrand model with differentiated goods, and the Varian model) and highlight their conceptual relationships.

In Section 5, we re-evaluate the criticism advanced against the viability of de-idealizations in economics in the light of our case-study. After proposing a working definition of de-idealized models, we argue that critics tend to underestimate the importance of de-idealization techniques in economic modeling. Indeed, a striking contrast exists between the claim that de-idealizations are unfeasible and the economists' effort to relax idealized assumptions to get models with better explanatory and predictive power. We conclude that such criticism is ultimately ill-founded, and that de-idealization strategies 
are not only possible but also actually employed in economics. Finally, in section 6 we summarize our discussion and provide a tentative assessment of its implications for the ongoing discussion of realism, progress, and related issues in economic methodology.

\section{Are There De-idealizations in Economics?}

Both scientists and philosophers widely agree that idealizations are ubiquitous and unavoidable in science. As Potochnik $(2017,2)$ puts it:

Most basically, a science practiced by limited human beings in a complex world results in widespread idealization. Idealizations are assumptions made without regard for whether they are true, generally with full knowledge that they are false. Classic examples are the assumption of a frictionless plane in physics and the assumption of perfectly rational agents in economics. Despite their falsity, idealizations appear in almost every scientific project and product.

Finding examples of idealized theories and models in science is indeed not difficult. In this paper, we shall focus on economic theory (and the theory of industrial organization in particular). Even within this field, examples of idealized assumption abound: from perfect rationality (as Potochnik notes in the above quotation) to perfect mobility, zero transaction costs, perfectly divisible goods, full employment, and so on. Idealizations are indeed typical and widespread in economics, and virtually all economic models contain assumptions that are idealized to at least some degree (Mäki 1992, 324).

Given that idealizations are central and ubiquitous to most scientific disciplines, it is no surprise that philosophers of science devoted much attention to this notion. Different scholars studying idealizations in science (and related notions like abstraction or isolation) have proposed different ways of classifying and understanding idealized assumptions, models, and theories (Musgrave 1981; McMullin 1985; Cartwright 1989; Mäki 2000, 2012, 2020; Hindriks 2006; Weisberg 2007, 2013; Wimsatt 2007; Levy 2018). ${ }^{1}$ Such proposals resulted in a interesting debate on the nature of idealized assumptions and on the role they play, especially in theoretical models. In particular, philosophers have acknowledged that scientists may employ idealized assumptions for a variety of purposes including isolating the essence of the

1. The concept of "idealization" and its related notions - isolation, abstraction, etc. have been discussed by many leading authors in the history of social science (from Johann von Thünen, John Stuart Mill and Max Weber to Milton Friedman and Thomas Schelling). In our paper, however, we shall focus mainly on the recent literature in the philosophy of science about idealizations and modeling. 
problem (Nowak 1980), isolating causal mechanisms (Mäki 1992, 1994), improving mathematical tractability (Alexandrova 2006; Knuuttila 2009), use as a benchmark ${ }^{2}$ (Mäki 2020), and others.

While the debate is not settled, and there is no unified view of the nature and role of idealizations in science, it seems fair to say that most philosophers would agree on a common understanding of what idealized models and theories are (217). According to such a "minimal" definition, an idealization has at least the following two properties. First, it is a deliberate falsehood: an idealized assumption appearing (even not explicitly) in a theoretical model is a proposition which is known to be false when applied to real-world phenomena in the target domain. Second, idealized assumptions usually concern some parameter appearing in the formulation of the theory or model assuming a certain extreme value - typically zero or infinite that is known to be unrealistic. ${ }^{3}$ In the next sections, we shall consider some concrete examples of how idealizations work in science; for the moment, the above minimal definition will suffice to illustrate the purpose of this paper.

Interestingly, while the idea of idealization is widely studied and central to the recent philosophical debate, the companion notion of de-idealization has attracted less attention. Roughly, de-idealizing a theory or model means removing one of its idealized assumptions and replacing it with a new one that it is less idealized, i.e., more realistic in being closer to the actual phenomena. To quote again Potochnik's example, studying the effect of friction on the motion of objects moving down an inclined plane leads to developing a model that is de-idealized with respect to Galileo's original one.

At first sight, de-idealizations are as important as idealizations are in science. This was emphasized long ago by Leszek Nowak and his followers (the so-called Poznań School), who studied in detail the notion of de-idealization under the label of "concretization." According to Nowak, scientists often engage in what we can call an idealization-concretization strategy, by which highly idealized models are replaced by less idealized models.

In turn, Nowak defends the view that scientific progress can be construed as the development of increasingly more de-idealized theories and models, which are more realistic and hence superior than their predecessors.

Interestingly, some authors have explored the applications of Nowak's idealization-concretization strategy to economics. For instance, Cools, Hamminga, and Kuipers (1994) discuss the Modigliani-Miller theorem as an ide-

2. As Mäki (cf. 2020, 229) notes, Max Weber's concept of "ideal type" is a clear example of the use of idealization as benchmark insofar as real situations can be compared and understood in terms of deviations from ideal types. For instance, the impact of irrational behavior on economic decisions can be understood and explained only starting from the ideal behavior of the homo oeconomicus.

3. Rice (2019) has recently argued that one cannot decompose a model into parts that are idealized and parts that are not. This does not seem to be in conflict with the minimal view just presented, which only requires that idealizations are acknowledged as falsehoods and modeled in terms of extreme values. 
alized law in Nowak's sense, and interpret subsequent modifications of the model - taking into account, for instance, corporate taxes and bankruptcy - as de-idealizing steps. In his defence of scientific realism in economics, Hindriks (2012) studies a series of theories developed for measuring the markup ratio of price over marginal cost that gradually relaxed the idealized assumptions of constant productivity growth and constant return to scale. Notably, he argues that economists aim to develop true theories using, among others, the so-called future-truth strategy, according to which the idealized assumptions contained in a model are progressively relaxed with more realistic ones. Consonant views have been advanced also by Niiniluoto (2002, $2012,2018)$ who suggests that at least some of the historical changes in economic theorizing can be interpreted in this way as improvements toward models and theories which are "closer to the truth" than their predecessors. We shall come back to these ideas in the final Section 6 below.

Contrary to the above view, that sees de-idealization or concretization as a central notion in the methodological analysis of scientific models, some authors have recently argued that de-idealization strategies hardly work when applied to economic models and, therefore, are seldom used by economists (Alexandrova 2008; Alexandrova and Northcott 2009; Reiss 2012). For instance, Julian Reiss $(2012,379)$ bluntly argues that

De-idealization strategies don't normally work and are therefore seldom employed [...]. Economics of information, transaction cost economics or the economics of imperfect competition do not provide de-idealized versions of the 'standard partial equilibrium model' with perfect information etc. - they're rival models.

According to Reiss, de-idealization strategies do not work because of the very peculiar way in which economists build their models. Generally speaking, the vast majority of theoretical economic models are mathematical models that describe the equilibrium of a market composed of rational, maximizing agents. This plain fact, Reiss argues, prevents the possibility of implementing de-idealization strategies where only a single assumption of a model is modified while holding everything else constant. In his own words:

Because of the high standards of mathematical elegance, equilibrium solutions, methodological individualism and rationality economics models must comply with, it is not normally possible to tinker with individual assumptions that are deemed 'too highly idealized for the purpose at hand' while leaving others fully intact when building a new, less idealized model. (379)

A consonant position is advanced by Alexandrova (2008) and Alexandrova and Northcott (2009). Their own example concerns auction theory where, they argue, de-idealizations of unrealistic assumptions are hardly ever carried out: 
Some clearly unrealistic assumptions included perfect rationality of bidders, the number of objects for sale, absence of budget constraints on the part of bidders, etc. The technique of de-idealization could not be applied to any of these. [...] Even at an abstract level there was no one theoretical model that was supposed to represent the actual auction. (Alexandrova 2008, 389)

In sum, according to such authoritative voices, the concept of de-idealization has no real role to play in the analysis of how economists develop, assess, and change their models. In this paper, we aim to show that this pessimism about de-idealization in economics is unfounded. To this purpose, in the next section we present in more detail the role of idealization as applied to economic models. We then discuss a case study taken from the theory of industrial organization and, in Section 5, we come back to the arguments advanced by the critics against that view.

\section{Idealizations and De-idealizations: Setting the Stage}

Before considering the case of economic modeling, let us start with a classical example of the method of idealization and de-idealization as discussed by Nowak (1980), i.e., the ideal gas law, also known as Clapeyron's law (or Clausius-Clapeyron's equation). As the name suggests, the law introduces some idealized assumptions in order to describe the behavior of a hypothetical ideal gas, which is however a good approximation of many real gases. Denoting $P, V$ and $T$ the pressure, volume and temperature of the gas, respectively, and $R$ the ideal gas constant, the law states that in equilibrium:

$$
P V=R T
$$

Crucially, Clapeyron's law makes two idealized assumptions concerning the particles composing the gas: first, that all the forces of interaction $a$ between these particles are negligible; second, that the same holds for the volume $b$ of each particle. According to Nowak, an adequate formulation of Clapeyron's law - which makes clear that it concerns the behavior of an ideal gas composed of many randomly moving point particles that are not subject to inter-particle interactions - is hence the following:

$$
\text { if } a=0 \text { and } b=0 \text { then } P V=R T
$$

The conditional form of the law highlights its idealized nature; moreover, it also invites reasoning about its possible concretizations, corresponding to the cases where either $a$ or $b$, or even both, are not negligible and hence 
different from zero. In the latter case, one obtains the van der Waals's law, which can be viewed as a de-idealization of Clapeyron's law:

$$
\left(P+a / V^{2}\right)(V-b)=R T
$$

The above law takes into account the influence of inter-molecular attractive forces $(a)$ and the finite size of the gas particles $(b)$, specifying what happens when both the conditions appearing in the antecedent of the original law in conditional form are false. Note that, if one puts $a=0$ and $b=0$ in equation 3, one obtains again the original Clapeyron's law in (1). In this sense, the idealized law is a special case of the more general (and complex) de-idealized law.

According to the Poznan School, science is littered with laws containing idealized assumptions, and scientists routinely employ the strategy of idealization and de-idealization in order to develop their models and theories. Such strategy can be described in abstract terms as follows. One starts with a law governing the behavior of some objects $x$ and expressing a functional dependence of a quantity $F(x)$ on a finite number of other quantities $q_{1}(x), \ldots, q_{n}(x)$. In the simplest case, where $n=1$, the law has the form:

$$
F(x)=f_{0}(q(x))
$$

In most cases, equation (4) ignores the influence of some relevant factors $w_{1}(x), \ldots, w_{k}(x)$, which however do affect the behavior of $x$ beyond the considered factor $q$. In other words, equation (4) is an idealized law which assumes that $w_{1}(x), \ldots, w_{k}(x)$ are all negligible and equal to zero (or to some suitably specified value $\left.{ }^{4}\right)$. If just one such factor $w_{1}$ is ignored, the proper form of the law is expressed as follows:

$$
\text { if } w_{1}(x)=0 \text { then } F(x)=f_{0}(q(x))
$$

The conditional form makes the role of the idealized assumption concerning $w_{1}(x)$ explicit: the value of the magnitude $w_{1}$ attributed to the object $x$ is assumed to be zero even though, as a matter of fact, this is not the case. ${ }^{5}$ De-idealizing such a law amounts to removing the idealized assumption by

4. To be more precise (cf. Nowak 1980, 28-29), here "zero" represents the minimum value that the magnitudes $w_{i}$ can meaningfully assume in the relevant context. In some cases, as with the Clapeyron's law seen above, this is actually zero. In others, this zero-value represents some relevant constant, meaning for instance that the change in the quantity $w_{i}$ is zero, or that some ratio of relevant factors is constant, and so on (see Section 4.1 for an example). In short, in an idealized law or model, some parameter assumes an extreme value (not necessarily 0 ) which is unrealistic and makes some quantity or factor negligible in the relevant context. We thank an anonymous reviewer for prompting us clarifying this point.

5. Here we neglect the semantic problem concerning how to interpret Nowak's idealized laws. See Niiniluoto (2002, 2018). 
taking into account the ignored factor $w_{1}$, thus obtaining a new, de-idealized law with the following form:

$$
\text { if } w_{1}(x) \neq 0 \text { then } F(x)=f_{1}\left(q(x), w_{1}(x)\right)
$$

In principle, this process can be repeated, in a step-wise fashion, for any other factor that scientists find important to take into account, leading to more and more complex, and de-idealized, versions of the original law.

Nowak's approach, as outlined above, provides a quite abstract framework to deal with idealizations and de-idealizations as far as mathematical laws are concerned. To the best of our knowledge, a formal definition of "idealized" and "de-idealized" models comparable in rigor to Nowak's one for laws remains to be developed. ${ }^{6}$ Still, it is not difficult to find, in the economic literature, examples of more or less idealized models that are connected to each other by relations that can be quite naturally construed as de-idealization relations in Nowak's sense. Let us briefly mention but one example, that we discuss later in detail, of how de-idealization strategies work in the case of economic models.

The theory of industrial organization ("IO theory" for short) is a branch of economics which deals with the strategic behavior of firms in imperfectly competitive markets and with its implications for policy related topics such as antitrust regulation and mergers (i.e., two separate firms that join together to form a single one). A large part of current IO theory focuses on oligopolies, i.e. markets with a small number of large sellers (so-called oligopolists) and a big number of consumers that demand the goods produced by those firms. One core model of IO theory is the so-called Bertrand model; it concerns a simple market containing just two firms, both producing exactly the same good at constant marginal costs. Clearly, many assumptions of this model are highly idealized: to mention but a few, perfect homogeneity of goods, perfect information among consumers, no capacity constraints, constant marginal costs, profit maximization and so on. With such highly unrealistic assumptions, one is able to prove that the equilibrium price in the market equals the marginal cost - a result which is hardly ever supported by empirical evidence and, for this reason, is known as the "Bertrand paradox."

Economists have reacted to the Bertrand paradox in various ways, often developing new models that modifies the original one by relaxing one or the other of its unrealistic assumptions. A case in point is the assumption of perfect homogeneity, which is a clear instance of an idealization, since realworld markets are characterized by a sharp degree of product differentiation in terms of physical characteristics, location, and consumers' tastes. ${ }^{7}$ What

6. In Section 5, we make an attempt to provide such a definition. See also Knuuttila and Morgan (2019) for a detailed analysis of many aspects of the notion of de-idealization.

7. Eaton and Lipsey (1989) provide an extensive treatment of product differentiation. See also Belleflamme and Peitz (2015, Chapter 5). 
is known in the literature as the "Bertrand model with differentiated goods" (henceforth, the "D-Bertrand model" for brevity) has been developed exactly to avoid the assumption of perfect homogeneity and to account for product differentiation. The new model keeps essentially unaltered all the assumptions of the Bertrand model, but assumes that the two firms produce two different goods (e.g., Coca-Cola and Pepsi). In this way, the D-Bertrand model can account for product differentiation and make sense of firms' market power, thus avoiding the Bertrand paradox (see section 4.1 for details).

The above example makes clear some general features of idealizations and de-idealization in economics that are worth noting. First, both the Bertrand and the D-Bertrand model aim at describing oligopolistic markets. Second, while both models are highly simplified and hence idealized, the D-Bertrand model is less idealized that the Bertrand model, since it avoids the perfect homogeneity assumptions that the latter makes. Third, and crucially, the DBertrand model provides a measure of product differentiation which allows one to say how diverse are the two goods on the market; when such measure is negligible, the original Bertrand paradox re-appears, and the two models basically collapse on each other. In this sense, the D-Bertrand model deidealizes the standard Bertrand model in a similar fashion to how van der Waals's law de-idealizes Clapeyron's law.

As we shall better argue in Section 5, the notions of idealization and de-idealization, understood in a broadly Nowakian sense, provide a fruitful and viable to analyze the theory and practice of economic modeling. To corroborate our thesis, in the next section we present in some detail three different models within IO theory, exploring their conceptual relationships in the light of our previous discussion.

\section{Case Study: Models of Oligopoly Pricing}

The French engineer Joseph Bertrand (1883) introduced his model while discussing another classical contribution to the theory of oligopoly, the Cournot model. Later, Francis Edgeworth (1925) further developed Bertrand's ideas and today the Bertrand model of oligopoly pricing is part of standard IO textbooks.

The Bertrand model describes the interaction among sellers and buyers in a highly idealized market, with the goal of predicting the price charged by sellers. It considers two firms 1 and 2 (the sellers), both of which produce the same homogeneous good at identical constant marginal costs $c$. The firms simultaneously set prices in order to maximize profits. On the demand side of the market, there are the firms' customers (the buyers), who always buy from the cheapest seller. The demand function faced by firm 1 is simply defined as follows, where $Q_{1}\left(p_{1}\right)$ is the quantity of the good demanded by the buyers at price $p_{1}$ : 


$$
Q_{1}\left(p_{1}\right)= \begin{cases}Q\left(p_{1}\right) & \text { if } p_{1}<p_{2} \\ Q\left(p_{1}\right) / 2 & \text { if } p_{1}=p_{2} \\ 0 & \text { if } p_{1}>p_{2}\end{cases}
$$

In words, this means that, since consumers are fully responsive to changes in prices, when firm 1 charges a lower price than firm 2, the former attracts the entire demand. Conversely, if firm 1 charges a higher price than firm 2, then no consumers will buy from 1. Finally, if both firms charge the same prices, then the demand is equally split between the two firms. The demand function of firm 2 is defined in the same way, just replacing " 1 " with "2" in the above formula.

In this model setup, a single Nash equilibrium in pure strategies exists where both firms set prices equal to their marginal costs. This is easily seen by noting that, for all other price combinations, at least one firm has an incentive to deviate, i.e., to set a price different from $c$. If $p_{1}>p_{2}>c$, then the firm 1 can increase its profits by setting a price $p_{1}^{\prime} \in\left(c, p_{2}\right)$; if $p_{1}=p_{2}>c$, then each firm can slightly undercut the rival price to increase profits; if $p_{1}>p_{2}=c$, then firm 2 can increase its profits by increasing price above $c$ and just below $p_{1}$. Thus, $p_{1}^{*}=p_{2}^{*}=c$ is the unique Nash equilibrium of the game (the star denoting equilibrium prices).

This result - known as the "Bertrand paradox" - shows that price competition between two firms is sufficient to equalize all prices at the level of the marginal cost. This is called a paradox since, in real markets, this does not happen. Indeed, even a casual observation of economic reality immediately suggests that firms usually set their prices above their marginal costs, i.e., they have at least some form of "market power." As a consequence, a great deal of work within industrial economics has been devoted to understanding where market power comes from and how firms manage to raise their prices above marginal costs in the face of Bertrand's result.

Researchers in IO have identified two main sources of firms' market power in oligopolistic markets. First, goods are almost never perfectly homogeneous. Second, consumers normally experience a degree of inertia whereby they are not fully susceptible to changes in price. The first aspect of real (as opposed to idealized) markets is known as "product differentiation," the second as "consumer inertia." In the remaining part of this section, we consider two well-known models - i.e., the Bertrand model with differentiated goods and the so-called Varian model - that take into account, respectively, product differentiation and consumer inertia.

In the next section, we shall argue that these two models can be construed as two different de-idealizations of the original one in the sense defined in Section 3. 


\subsection{The Bertrand Model with Differentiated Goods}

The standard Bertrand model assumes that products are perfectly homogeneous so that consumers cannot differentiate among brands or distinguish among the producers when purchasing a specific product. Economists find this assumption highly unrealistic for the majority of markets and they employ various approaches to modeling industries producing differentiated products. Here we follow the approach developed by Dixit (1979) and Singh and Vives (1984). Their idea is pretty simple: two firms produce two differentiated products facing a linear inverse demand curve from consumers that gains utility from consuming a variety of goods. ${ }^{8}$

Suppose that two firms produce differentiated brands of a soft drink e.g. Coca-Cola and Pepsi - with linear inverse demand functions (brands' prices as functions of quantities):

$$
\begin{aligned}
& p_{1}=\alpha-\beta q_{1}-\gamma q_{2} \\
& p_{2}=\alpha-\gamma q_{1}-\beta q_{2}
\end{aligned}
$$

where $\left(p_{1}, q_{1}\right)$ and $\left(p_{2}, q_{2}\right)$ are the price and quantity of, respectively, CocaCola and Pepsi, and $\alpha, \beta, \gamma \in \mathbb{R}$ are parameters. Note that, contrary to what happens in the original Bertrand model, equations (8) and (9) together imply that the price for Coca-Cola depends both on the quantity of Coca-Cola and on the quantity of Pepsi, and vice-versa. Moreover, it is assumed that $\beta>0$ (to have standard downward sloping demand curves) and that $\beta^{2}>\gamma^{2}$. The latter assumption is crucial since it implies that the price of a good is more sensitive to a change in the quantity of that good than to a change in the quantity of the other one. In the jargon of economists, this means that the "own-price effect" dominates the "cross-price effect."

By inverting (8) and (9) we find the system of direct demand functions (quantity demanded as functions of brands' prices):

$$
\begin{aligned}
& q_{1}=a-b p_{1}+d p_{2} \\
& q_{2}=a+d p_{1}-b p_{2}
\end{aligned}
$$

where

$$
\begin{gathered}
a=\frac{\alpha(\beta-\gamma)}{\beta^{2}-\gamma^{2}} \\
b=\frac{\beta}{\beta^{2}-\gamma^{2}}>0 \\
d=\frac{\gamma}{\beta^{2}-\gamma^{2}}>0
\end{gathered}
$$

8. As economists know, this is by no means the only way to modeling product differentiation. Another well-known approach is the so-called "location approach," originated by the seminal article by Hotelling (1929). Both approaches are now part of standard IO textbooks such as Shy (1995), Martin (2010), and Belleflamme and Peitz (2015). 


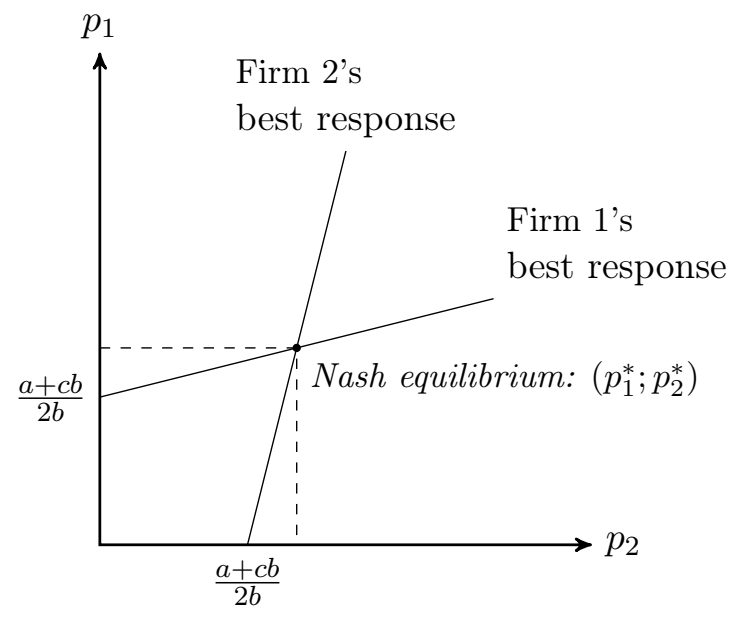

Figure 1: The D-Bertrand model: Nash equilibrium price is given by the intersection between firms' best response to each other. The best-response functions are upward sloping, meaning that if one firm raises its price, the other would respond by raising its price as well. The value $\frac{a+c b}{2 b}$ is the optimal price charged by each firm when the other one sets the price equal to zero; formally, it is the intercept of the two best response functions with the axes.

The appealing feature of this setup is that one can formally define a measure $\delta$ of product differentiation, as follows:

$$
\delta=\frac{\gamma^{2}}{\beta^{2}}
$$

This means that two products are highly differentiated when the cross-price effect tends to zero, i.e. $\gamma^{2}=0$ and, therefore, $\delta=0$. Intuitively, consumers perceive products so differently that a change in the price of Coca-Cola has little or no influence on the demand for price of Pepsi. Conversely, the two products are perfectly homogeneous when the cross-price effect is equal to the own-price effect, i.e., $\gamma^{2}=\beta^{2}$ and, therefore, $\delta=1$. This means that if consumers consider the two products as almost homogeneous, a change in price of Coca-Cola will have a great influence on the demand of Pepsi. This is the mechanism that we saw at work in the standard Bertrand model: a slight difference in price causes a great shift in consumers' demand.

As for the standard Bertrand model, it is assumed that firms simultaneously set prices in order to maximize profits given identical constant marginal $\operatorname{costs} c$. The unique Nash equilibrium (see Figure 1) can be found by considering the mutual best-responses of firms (i.e., the profit-maximizing price of Coca-Cola for an arbitrary price by Pepsi and vice-versa):

$$
p_{1}=\frac{a+d p_{2}+c b}{2 b}
$$




$$
p_{2}=\frac{a+d p_{1}+c b}{2 b}
$$

and, thus,

$$
p_{1}^{*}=p_{2}^{*}=\frac{a+c b}{2 b-d}=\frac{\alpha(\beta-\gamma)}{2 \beta-\gamma}+\frac{c \beta}{2 \beta-\gamma}
$$

Prices and profit levels increase when products are more differentiated, i.e. when $\gamma$ tends to zero. This means that product differentiation increases the market power of firms by relaxing price competition. Conversely, prices and profit levels decrease when the products become less differentiated, i.e. when $\gamma$ tends to $\beta$. By the way, this explains why Coca-Cola and Pepsi spend millions on advertising to convince consumers about the uniqueness of their products.

The D-Bertrand model is a cornerstone of modern industrial organization. First, it sheds light one important source of corporate market power. Second, it plays a prominent role in contemporary merger analysis where it is employed to predict the post-merger equilibrium prices after being calibrated using data from a given industry (Werden, Froeb, and Scheffman 2004; Einav and Levin 2010). For our purposes, what is important to note is how this models compares with the original Bertrand model. In this connection, one can easily check that the Bertrand paradox - i.e., the result that $p_{1}^{*}=p_{2}^{*}=\mathrm{c}-\mathrm{can}$ be obtained as a special case of the new model when $\gamma=\beta$ or, equivalently, $\delta=1$ :

$$
\text { if } \delta=1 \text { then } p_{1}^{*}=p_{2}^{*}=\frac{\alpha(\beta-\beta)}{2 \beta-\beta}+\frac{c \beta}{2 \beta-\beta}=\frac{c \beta}{\beta}=c
$$

In other words, the original Bertrand model is a special case of the DBertrand model when the goods produced by the firms are perfectly homogeneous.

\subsection{The Varian Model of Sales}

A second source of firms' market power comes not from the intrinsic features of their products, but from exogenous elements characterizing their market environment. One of these elements is that some consumers may be more informed than others regarding the prices charged by different firms. The American economist Hal Varian (1980) famously exploited this fact in order to explain market power in a celebrated article published in the American Economic Review.

The setup of the Varian model is analogous to that of the standard Bertrand, except for relaxing the perfect information assumption, thus taking into account that some consumers are more informed than others about the market prices. More precisely, Varian assumes that two firms sell a homogeneous product competing on prices in order to maximize profits. Firms have unlimited capacity to supply this product at a constant marginal costs 
$c$. This market is served by a price information clearinghouse (e.g., a newspaper or an Internet price comparison site). A number $S$ of "informed" consumers consult the information clearinghouse and purchase at the lowest listed price. The remaining $U$ "uninformed" consumers, by contrast, do not consult the clearinghouse and choose a firm at random as long as the price does not exceed $v$. This implies that each firm attracts $U / 2$ uninformed consumers. All consumers have unit demand with a maximal willingness to pay of $v>c$.

As Varian shows, the heterogeneity, in terms of access to information, among consumers leads to different equilibrium prices than those predicted by Bertrand. More formally, while there is no equilibrium in pure strategies, a symmetric equilibrium in mixed strategies exists such that firms randomize prices. The intuition is the following: if one firm set its price deterministically (i.e. choosing a strategy with probability equal to 1 ), then the other firm could advantage by setting a lower price and thus capturing all informed consumers. Thus, firms find profitable to vary their prices over time, a phenomenon sometimes referred to as "temporal price dispersion"9 It can be proven (we sketch such a proof in the Appendix) that such a mixed-strategy equilibrium occurs when each firm charges a price $p$ in the interval $\left[p_{0}, v\right]$, where

$$
p_{0}=c+(v-c)\left(\frac{U / 2}{U / 2+S}\right)
$$

with cumulative probability $F(p)$ :

$$
F(p)=1-\left(\frac{(v-p)(U / 2)}{(p-c) S}\right)
$$

It is worth noting that price dispersion arises from the existence of an information clearinghouse which provides a subset of consumers with a list of prices charged by different firms in the market. Firms face a trade-off between lowering price to attract informed consumers (who would not buy at a price higher than the lowest one offered by the sellers) and keeping the price higher hoping to sell to uninformed customers. Thus, the two firms charge different prices for an identical good because of the heterogeneity in consumers' information.

Again, we are interested here in the relations between Varian's model and the standard Bertrand model. The crucial difference between the two models is the assumption, implicit in the latter one, that consumers can acquire information on prices at no cost. Varian relaxes this assumption differentiating informed and uninformed costumers. As a consequence, we can recover Bertrand's setup within Varian's model by assuming that, when

9. Temporal price dispersion seemingly happens in a wide range of contexts, from sales in retail markets to life insurance industry and Internet price comparison websites. See Baye and Morgan (2001) and Baye, Morgan, and Scholten (2006). 


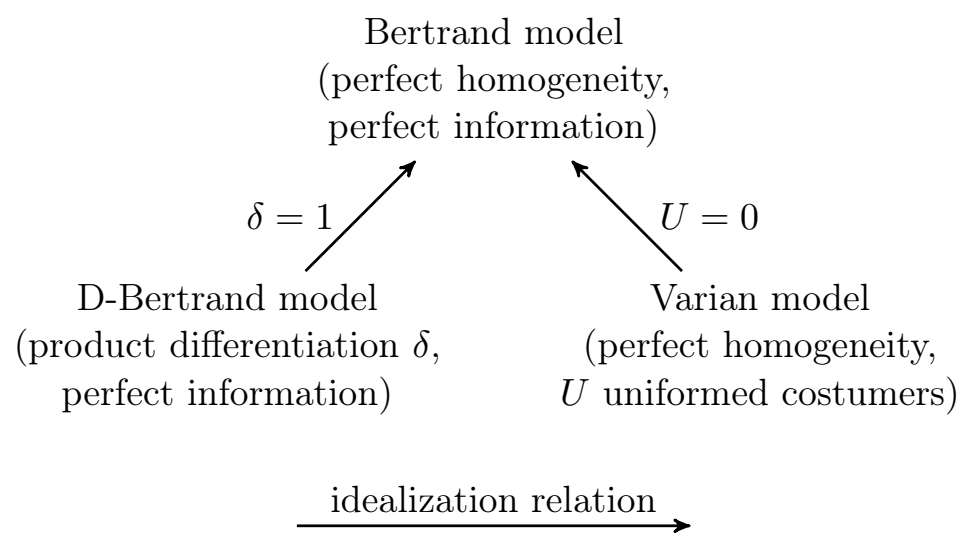

Figure 2: The Bertrand model with differentiated goods (D-Bertrand) and the Varian model as two different de-idealizations of the Bertrand model.

information costs are zero, all costumers become informed, i.e., $U$ is zero. In such case, the symmetric equilibrium distribution of prices is degenerate and the Bertrand paradox re-appears, with all firms pricing at marginal cost:

$$
\text { if } U=0 \text { then } p_{0}=c+(v-c) \cdot 0=c
$$

In short, if acquiring information is costless the Bertrand model turns out to be a special case of the Varian model.

\section{Defending De-idealization in Economic Modeling}

In the foregoing section, we considered three different models of oligopoly markets in order to show how de-idealization strategies apply to the practice of economic modeling. We began with the standard Bertrand model, which assumes, among others idealizations, both perfect homogeneity of goods and perfect information of consumers. We then considered two different models, each relaxing exactly one of these two idealizing assumptions. The DBertrand model accounts for product differentiation, thus abandoning the perfect homogeneity assumption. The Varian model introduces information costs and uninformed customers, thus abandoning the perfect information assumption. As we argued, both the D-Bertrand and the Varian models can be clearly construed as two different de-idealizations of the highly idealized Bertrand model. This is shown by the fact that if one starts from one of the de-idealized models and re-introduce the corresponding idealizing assumption (by assigning to the relevant parameter an adequate extreme value), one comes back to the original Bertrand model. These processes are synthetically represented in Figure 2, where arrows denote the introduction of idealized assumptions. 
As an upshot of our discussion so far, we can introduce the following tentative definition of de-idealized economic models. We shall say that a (mathematical) model $M_{2}$ is a de-idealization (or a de-idealized version) of another model $M_{1}$ when:

(i) both $M_{1}$ and $M_{2}$ aim at modeling the same phenomenon or domain $T$, what we call their "target";

(ii) with reference to $T, M_{1}$ contains at least one idealized assumption which is not contained in $M_{2}$; in this sense, $M_{2}$ is more "T-realistic" than $M_{1}$;

(iii) $M_{1}$ is a special case of $M_{2}$, i.e., $M_{1}$ can be obtained from $M_{2}$ by assigning some specific value to some parameter of $M_{2}$.

It should be clear how the above conditions apply to our case-study. With reference, for instance, to the D-Bertrand model one can see that: (i) the Bertrand and the D-Bertrand model aim at describing the same target $T$, i.e., a simple market where two firms set prices facing the demand from many consumers; (ii) the D-Bertrand model relaxes the perfect homogeneity assumption of the Bertrand model and accounts for product differentiation, thus being more realistic with respect to $T$; (iii) when the degree of product differentiation tends to zero (i.e., measure $\delta$ tends to 1 ), the standard Bertrand can be obtained as a special case of the D-Bertrand model. In short, the D-Bertrand model can be construed as a de-idealized version of the standard Bertrand model.

Similar considerations can be repeated as far as the relations between the Varian and the Bertrand models are concerned. Again, the two models share the same target $T$ as above, and the Varian model is more $T$-realistic than the other, since it relaxes the assumption of perfect information of customers; moreover, when such assumption is re-introduced (i.e., when the number $U$ of uninformed consumers is 0 ), the Bertrand model can be recovered as a special, idealized case of the Varian model.

The definition proposed above is surely incomplete and in need of improvement; still, we believe it captures, as our case-study shows, some important features of the actual practice of economic modeling. Moreover, it allows us to put in perspective the criticism advanced against the viability of de-idealization strategies in economics that we presented in Section 2. For instance, Reiss's skepticism about de-idealizations essentially boils down to the claim that less idealized models are not de-idealized versions of more idealized ones, but they are plainly "rival models" (Reiss 2012, 379). According to Reiss (2012, ibidem),

it is not normally possible to tinker with individual assumptions that are deemed 'too highly idealized for the purpose at hand' 
while leaving others fully intact when building a new, less idealized model [...] when a factor is deemed too important to be ignored, the framework is changed altogether.

This may well be true for some of the examples Reiss has in mind, but this is not sufficient to conclude that "de-idealization strategies don't normally work and are therefore seldom employed" in economics (Reiss 2012, 379). Indeed, we believe that the previous discussion of our case-study shows that exactly the opposite is true.

Moreover, adopting Reiss's view would lead us to consider as rivals a whole range of models that economists consider to be extensions or special cases of other models. As a matter of fact, economists do not portray Bertrand's model with differentiated goods as a rival to the standard Bertrand but rather as one of its extensions. Even a quick glance at the major IO textbooks supports our observation; to quote but two examples:

We analyse here several models of price competition. We start with the standard Bertrand (1883) model where products are homogeneous. Then, we extend the model in two directions: first, we assume that firms have private information about their marginal costs of production; second, we consider differentiated products. (Belleflamme and Peitz 2015, 45)

Naturally, the analysis turns out to be much less extreme [...] if the stringent and somewhat unrealistic assumption of good homogeneity is relaxed. (Vega-Redondo 2003, p. 81)

In sum, we believe that only a careful analysis of specific case-studies can tell us whether, and to what extent, economists do employ de-idealization strategies in developing their models, as we suggest they do.

In this connection, a couple of more general remarks are in order. First, a de-idealized model can in turn be highly idealized and be subject to further de-idealizations. For instance, the Varian model assumes, besides the perfect homogeneity of goods, that it is costless for firms to list prices on the clearinghouse. However, real-world firms are normally charged a certain amount to advertise their prices on newspapers or websites. For this reason, new models have been built that relax this idealized assumption and allow firms to decide whether to list their price at the clearinghouse. ${ }^{10}$ The original Varian model can then be obtained in the limiting case when advertising costs tend to zero (Baye, Morgan, and Scholten 2006, 352). This is another case of the de-idealization strategy at work, consistent with the idea defended here that the de-idealization process occurs in a progressively step-wise fashion.

10. See Baye and Morgan (2001), Baye, Morgan, and Scholten (2006), and Shelegia and Wilson (2021). These authors show that equilibrium price dispersion arises - provided that advertising costs are not too large that firms refuse to list prices at the clearinghouse. 
This is the idea that Reiss seems to critique when, in his attack on realism in economics, he writes:

A final defence of realism in the light of the fact that all models are false is the Hegelian one of regarding models not individually but as a sequence progressing towards perfection. Individual models may well be false but error is eliminated progressively through de-idealization, de-isolation and the like. (Reiss 2012, 379)

As the epithet "Hegelian" suggests, however, this is too a simplistic understanding of how the de-idealization strategy works. As our case-study clearly shows, the de-idealization process does not need to be thought as a linear, indefinite sequence of models, each less idealized than the previous one, tending, so to speak, to some Hegelian, entirely de-idealized, final model. In fact, even a quick glance at Figure 2 shows that this process may well evolve in a tree-like fashion, with multiple de-idealized models obtained from the same model, which may be quite unrelated to each other. Indeed, in our example, it is not clear in what sense the D-Bertrand and Varian model are comparable except that they are both descendant of the standard Bertrand model. To recall, while the D-Bertrand model relaxes the assumption of product homogeneity but not that of perfect information, the opposite is true for the Varian model. These two models gave rise to two rather different strands of economic literature and their convergence toward a single, "final" model where both idealized assumptions are relaxed is at least uncertain, if not unlikely. Such convergence toward a fully de-idealized model may well happen, but it is not necessarily the case; only further theoretical and empirical research, rather than general philosophical claims, may decide the issue. In any case, such convergence is not necessary to support the view that deidealization strategies are used by economists. Indeed, our previous analysis is not affected by whether the tree structure depicted in Figure 2 converges to a single de-idealized model or diverges in a sort of bush-like family of models.

Finally, let us consider the critique of de-idealization advanced by Alexandrova (2008) and Alexandrova and Northcott (2009). These authors construe de-idealization as a strategy to test the robustness of the model, i.e., to investigate whether the conclusions of a model still hold if we change some of its theoretical assumptions. More specifically, de-idealizing a model aims to find the minimal set of assumptions such that a characteristic result holds:

The point of de-idealization is to check that the relationship observed in the original model [...] would still hold once some of the assumptions of the original model were no longer satisfied. (Alexandrova 2008, 388) 
While they acknowledge the usefulness of this strategy — when "the deidealization process is successful and the model's result applies" (Alexandrova and Northcott 2009, 311) —, they also believe that "at least as far as economics is concerned, such happy cases may be hard to come by" (ibid.). In particular, as already recalled in Section 2, they discuss a case-study from auction theory to argue that de-idealizations of unrealistic assumptions are hardly ever carried out.

In this regard, two comments are in order. First, even taken for granted that de-idealization is unfeasible in auction theory, this does not mean that it cannot be useful in other fields of economics. As Alexandrova $(2008,389)$ herself frankly admits, the fact that de-idealization strategies are seldom used in auction theory "does not discredit the technique of de-idealization - we do know how to de-idealize some albeit not all assumptions". Second, and contrary to what Alexandrova and Northcott seem to believe, we maintain that a relevant difference exists between the epistemic goal of robustness analysis and that of de-idealization techniques. Robustness analysis is performed to discover the minimal set of assumptions which is essential for deriving a given result within the model (Kuorikoski, Lehtinen, and Marchionni 2010). De-idealization, on the other hand, amounts to replacing a false, unrealistic assumption with a more realistic one in order to obtain a better model from an explanatory and predictive point of view. This distinction, we maintain, is crucial. In fact, as our case-study shows, when one de-idealizes a model, one typically finds new and different results from those that could be derived from the original model. For instance, price dispersion among firms is a result derivable in the Varian model, but not in the Bertrand model. This may be problematic from the point of view of robustness analysis but not from that of the de-idealization strategy. In short, while robustness analysis aims at deriving the same results from a different set of assumptions, the whole point of de-idealization is instead deriving different, more realistic results from it.

\section{Concluding Remarks and Future Work}

The main claims advanced in this paper can be summarized as follows: first, the notion of de-idealized (economic) models is sound and viable as a way of analyzing the relations between different but connected models; second, economists routinely employ de-idealization techniques in order to develop better models; third, the pessimistic outlook of some critics about such techniques is either unfounded or misplaced.

We are aware that a single case study is not enough to substantiate a fully-fledged methodological claim. On the other hand, we believe that the conceptual schema we settled can be adapted to many other economic contexts both within and outside IO theory. Let us consider, for instance, 
the case of macroeconomic theory. In this area, one finds both "classical" business cycle models developed in the 1980s and more recent models commonly adopted in contemporary macroeconomics - the so-called dynamic stochastic general equilibrium (DSGE) models. Both kinds of models share some crucial idealized assumptions: for instance, intertemporal utility maximization and the rational expectations hypothesis; however, the DSGE models de-idealize classical ones by taking into account imperfect competition, nominal rigidities, and monetary policy shocks (cf. Romer 2019). For this reason, Kuorikoski and Lehtinen $(2018,254)$ recently argued that model development in macroeconomics proceeds by "vertical expansion in that new modifications and 'improvements' are added to the generally accepted but in itself simplified and idealized core model to improve its realisticness and empirical accuracy." Another compelling example would concern behavioral economics models and their possible interpretation as de-idealized versions, in the sense described here, of neoclassical models. For instance, the model of other-regarding preferences by Fehr and Schmidt (1999) or the hyperbolic discounting function popularized by Laibson (1997) are interesting case studies to which our arguments are arguably applicable. Indeed, some leading behavioral economists seem to endorse the view that behavioral models could be seen as de-idealizations of neoclassical models. For instance, Sanjit Dhami $(2016,2)$ opens his advanced textbook on the Foundations of Behavioral Economic Analysis with the following claim:

Behavioral economics is an enhancement of neoclassical economics to take account of more empirically supported evidence on human behavior, and not its antithesis. Second, there is no paradigmatic battle between behavioral economics and neoclassical economics. As in every science, we progress by taking account of evidence that suggests a refinement and improvement of existing models.

These and many other case studies deserve a separate study, that we have to leave to a future occasion. In this connection, we acknowledge that the present paper is only a first step toward a fully defensible account of the method of idealization and de-idealization in economics, let alone in other scientific disciplines. To this purpose, one should better develop and defend the definition of de-idealized models presented in Section 5; study the logical properties of the relation " $M_{2}$ is a de-idealization of $M_{1}$," where $M_{1}$ and $M_{2}$ represent scientific models in general; and explore its applicability to further case-studies in different domains besides IO theory. Again, these are all topics whose discussion is left for the future.

Finally, in this paper we remained entirely silent on some crucial philosophical issues in economic methodology, to which our argument is clearly relevant. One has been much discussed in recent literature, and concerns the 
virtues of pluralism in economic theorizing and practice. In the aftermath of Rodrik's Economic Rules (Rodrik 2015), many scholars have strongly defended the advantages and desirability of a greater pluralism in the methods, the aims and the topics of current economic research. Among them, several philosophers of economics started focusing their attention on families of models, rather than on single models, in order to discuss interesting methodological issues (Aydinonat 2018; Grüne-Yanoff and Marchionni 2018; Veit 2019; Gräbner and Strunk 2020; Lisciandra and Korbmacher 2021). Despite their different views on economic modeling, the shared idea is that knowledge accumulation in economics mainly proceeds "horizontally", i.e., by developing many different and sometimes mutually inconsistent models of the same target, each of which is only partial and highly context-sensitive. Here, we do not need to take stock of this discussion. What is worth noting, however, is that while the horizontal dimension of theoretical development in economics is clearly important, the "vertical" one should not be forgotten. As we argued in this paper, a crucial way in which economic modeling proceeds is the development of less idealized models, which relax some of the idealized assumptions of their predecessors. This vertical growth of (families of) economic models can take various forms (recall the discussion of Reiss's Hegelian metaphor in the last section), but it is clearly as fundamental as the horizontal one. For this reason, philosophers of economics attentive to scientific practice should study both types of theoretical development, and the notion of de-idealization discussed in this paper seems a fruitful tool to do this.

A second, interesting question concerns the issue of the "credibility" of economic models. Economist Robert Sugden (2000, 2009) introduced the notion of credibility in the philosophical literature, arguing that economic models depict credible but counterfactual worlds which however are sufficiently similar to some target, real-world situation. As Sugden $(2009,4)$ himself acknowledges, the notion of "credible model" is inherently vague and it has prompted a great deal of debate among philosophers of economics (cf. Grüne-Yanoff 2009). An interesting open issue for future work is to explore whether the notion of de-idealization discussed here can contribute to the literature on the credibility of economic models. Our conjecture, that we cannot defend here in detail, is that the de-idealization strategies discussed in this paper may at least partly explain the credibility of economic models. Indeed, if economists think that models can be increasingly made more adequate and realistic, this may in turn increases their confidence in at least some of them as reasonable depictions of the target domain. However, corroborating such a claim - i.e., that de-idealizing a model may lead, or even generally leads, to an increase in its credibility - would require notions of both de-idealization and credibility that are better and more rigorously defined than those available at present.

The credibility issue leads us to a third, and final, problem: that of real- 
ism and anti-realism. This is of course crucial also because, as recalled in Section 2, philosophers leaning toward realism have often invoked de-idealization as an important component of a realist view of scientific progress. The basic idea is that highly idealized models and theories can be improved via de-idealization, i.e., by developing less idealized models and theories which relax some of the idealized assumptions of the former and are, in this sense, more realistic. This suggests that scientific progress is possible via such process of de-idealization, and that at least some of the historical changes in a scientific discipline can be interpreted as improvements toward models and theories which are less idealized and "closer to the truth" than their predecessors. This "verisimilitudinarian" view of progress, as based on the notion of verisimilitude or truthlikeness of theories and models (Popper 1963), has been long studied by philosophers (e.g. Cevolani and Tambolo 2013) and also applied to economics (Niiniluoto 2002, 2012). Further work is needed, however, to assess in detail the nature and role of idealized and de-idealized models in connection with the issues of progress and scientific realism, and to assess whether de-idealization strategies can contribute to the case for realism in economic methodology.

\section{Appendix. Equilibrium Price in the Varian model}

In this appendix, we show how to formally derive the equilibrium of the Varian model. Our proof is closely related to the original article by Varian (1980) and the later presentation of the model made in Varian $(1992,292-294)$. The main difference is that we fix the number of competing firms exogenously and we assume they have identical and constant marginal costs. ${ }^{11}$

Let $F(p)$ be the cumulative distribution function of the equilibrium strategy, that is the probability that a chosen price is lower or equal to $p$. Suppose that the firm 1 chooses $p$. If firm 2 chooses a price higher than $p$ (an event with probability $1-F(p)$ ), then $p$ is the lowest price and the firm 1 attracts all informed consumers $S$. Instead, if firm 2 chooses a price lower than $p$ (an event with probability $F(p)$ ), then firm 1 fails to have the lowest price and lose all informed consumers $S$. In the former case, the firm 1 gets a revenue of $(p-c)(S+U / 2)$ (all informed and its part of uninformed); in the latter case, it gets a revenue of $(p-c) U / 2$ (only its part of uninformed). In either case it pays a marginal cost $c$. Hence, the expected profits for the firm 1 are the following: ${ }^{12}$

$$
\pi=\int_{0}^{\infty}\{(p-c)(1-F(p))(S+U / 2)+(p-c) F(p) U / 2\} f(p) d p
$$

11. Varian determines the number of competing firms according to a zero profit condition and he assumes firms have zero marginal costs but identical fixed costs.

12. The problem is symmetric for the firm 2 . 
Note that every price charged in the equilibrium must yield the same expected profits, otherwise it would be profitable for the firm to increase the frequency with which it charged the more profitable prices relative to the less profitable. This means that it must hold:

$$
\pi=(p-c)(1-F(p))(S+U / 2)+(p-c) F(p) U / 2
$$

or, rearranging,

$$
F(p)=1+\frac{U / 2}{S}-\frac{\pi}{2 S(p-c)}
$$

To determine $\pi$ let us note that the probability that a firm charges a price less than or equal to the reservation price $v$ is 1 , so $F(v)=1$. Solving this equation gives us $\pi=(v-c) U$ and substituting into (25) we get:

$$
F(p)=1-\left(\frac{(v-p)(U / 2)}{(p-c) S}\right)
$$

The lower support of the distribution must satisfy $F\left(p_{0}\right)=0$, so that:

$$
p_{0}=c+(v-c)\left(\frac{U / 2}{U / 2+S}\right)
$$

Intuitively, pricing below $p_{0}$ is not beneficial since it does not attract additional consumers and yields lower profits. Eventually, no price above the reservation price $v$ will be charge because there is zero demand at any such price. Thus, $v$ is the upper support of $F(p)$.

Acknowledgements We wish to thank Francesco Guala, Kenan Huremović, Jesús Zamora Bonilla, the audiences at the ANPOSS/ENPOSS/POSSRT 2021 joint virtual conference and at the $61^{\text {st }}$ annual conference of the Italian Society of Economists (SIE), as well as two anonymous reviewers, for their very valuable discussion and comments.

Declaration of Conflicting Interests The authors declared no potential conflicts of interest with respect to the research, authorship, and/or publication of this article.

Funding Edoardo Peruzzi acknowledges financial support from the PEGASO PhD scholarship (POR FSE TOSCANA 2014/2020, Regione Toscana). Gustavo Cevolani acknowledges financial support from the PRIN project "From models to decisions" (Italian Ministry of University and Research grant n. 201743F9YE, IMT Lucca unit). 


\section{References}

Alexandrova, Anna. 2006. "Connecting Economic Models to the Real World: Game Theory and the FCC Spectrum Auctions." Philosophy of the Social Sciences 36 (2): 173-192.

Alexandrova, Anna. 2008. "Making Models Count." Philosophy of Science 75 (3): 383-404.

Alexandrova, Anna, and Robert Northcott. 2009. "Progress in Economics: Lessons from the Spectrum Auctions." In Oxford Handbook for Philosophy of Economics, edited by Harold Kincaid and Don Ross, 306-336.

Aydinonat, Emrah N. 2018. "The Diversity of Models as a Means to Better Explanations in Economics." Journal of Economic Methodology 25 (3): $237-251$.

Baye, Michael, and John Morgan. 2001. "Information Gatekeepers on the Internet and the Competitiveness of Homogeneous Product Markets." American Economic Review 91 (3): 454-474.

Baye, Michael, John Morgan, and Patrick Scholten. 2006. "Information, Search, and Price Dispersion." In Handbook on Economics and Information Systems, edited by Terrence Hendershott, 323-375. Bingley: Emerald.

Belleflamme, Paul, and Martin Peitz. 2015. Industrial Organization: Markets and Strategies. 2nd ed. First edition: 2010. Cambridge, UK: Cambridge University Press.

Bertrand, Joseph. 1883. "Review of Theorie mathematique de la richesse social and of Recherches sur les principes mathematiques de la theorie des richesses." Journal des Savants, 499-508.

Cartwright, Nancy. 1989. Nature's Capacities and Their Measurement. Oxford: Oxford University Press.

Cevolani, Gustavo, and Luca Tambolo. 2013. "Progress as Approximation to the Truth: A Defence of the Verisimilitudinarian Approach." Erkenntnis 78 (4): 921-935.

Cools, Kees, Bert Hamminga, and Theo Kuipers. 1994. "Truth Approximation by Concretization in Capital Structure Theory." In Idealization VI: Idealization in Economics, edited by Bert Hamminga and Neil De Marchi, 205-228. Amsterdam: Rodopi.

Dhami, Sanjit. 2016. The Foundations of Behavioral Economic Analysis. Oxford: Oxford University Press.

Dixit, Avinash. 1979. "A Model of Duopoly Suggesting a Theory of Entry Barriers." Bell Journal of Economics 10 (1): 20-32. 
Eaton, B. Curtis, and Richard G. Lipsey. 1989. "Product Differentiation." In Handbook of Industrial Organization, edited by Richand Schmalensee and Robert Willig, 1:723-768. Amsterdam: North-Holland.

Edgeworth, Francis Y. 1925. Papers Relating to Political Economy. Macmillan.

Einav, Liran, and Jonathan Levin. 2010. "Empirical Industrial Organization: A Progress Report." Journal of Economic Perspectives 24 (2): 145-62.

Fehr, Ernst, and Klaus M. Schmidt. 1999. "A theory of fairness, competition, and cooperation." Quarterly Journal of Economics 114 (3): 817-868.

Gräbner, Claudius, and Birte Strunk. 2020. "Pluralism in Economics: Its Critiques and Their Lessons." Journal of Economic Methodology 27 (4): 311-329.

Grüne-Yanoff, Till. 2009. "Preface to 'Economic Models as Credible Worlds or as Isolating Tools?" Erkenntnis 70 (1): 1-2.

Grüne-Yanoff, Till, and Caterina Marchionni. 2018. "Modeling Model Selection in Model Pluralism." Journal of Economic Methodology 25 (3): 265-275.

Hindriks, Frank. 2006. "Tractability assumptions and the Musgrave-Mäki typology." Journal of Economic Methodology 13 (4): 401-423.

Hindriks, Frank. 2012. "Saving Truth for Economics." In Economics for Real: Uskali Mäki and the place of truth in economics, edited by Aki Lehtinen, Jaakko Kuorikoski, and Petri Ylikoski, 43-64. London: Routledge.

Hotelling, Harold. 1929. "Stability in Competition." Economic Journal 39 (153): 41-57.

Knuuttila, Tarja. 2009. "Isolating representations versus credible constructions? Economic modelling in theory and practice." Erkenntnis 70 (1): 59-80.

Knuuttila, Tarja, and Mary Morgan. 2019. "Deidealization: No Easy Reversals." Philosophy of Science 86 (4): 641-661.

Kuorikoski, Jaakko, and Aki Lehtinen. 2018. "Model selection in macroeconomics: DSGE and ad hocness." Journal of Economic Methodology 25 (3): 252-264.

Kuorikoski, Jaakko, Aki Lehtinen, and Caterina Marchionni. 2010. "Economic Modelling as Robustness Analysis." British Journal for the Philosophy of Science 61 (3): 541-567.

Laibson, David. 1997. "Golden Eggs and Hyperbolic Discounting." Quarterly Journal of Economics 112 (2): 443-478. 
Levy, Arnon. 2018. "Idealization and abstraction: refining the distinction." Synthese, 1-18. https://doi.org/https://doi.org/10.1007/s11229-0181721-z.

Lisciandra, Chiara, and Johannes Korbmacher. 2021. "Multiple Models, One Explanation." Journal of Economic Methodology 28 (2): 186-206.

Mäki, Uskali. 1992. "On the Method of Isolation in Economics." In Idealization IV: Intelligibility in Science, edited by Craig Dilworth, 317-351. Amsterdam: Rodopi.

Mäki, Uskali. 1994. "Isolation, Idealization and Truth in Economics." In Idealization VI: Idealization in Economics, edited by Bert Hamminga and Neil De Marchi, 147-168. Amsterdam: Rodopi.

Mäki, Uskali. 2000. "Kinds of Assumptions and Their Truth: Shaking an Untwisted F-twist." Kyklos 53 (3): 317-335.

Mäki, Uskali. 2012. "The truth of false idealizations in modeling." In Models, Simulations and Representations, edited by Paul Humphreys and Cyrille Imbert, 216-233. Routledge.

Mäki, Uskali. 2020. "Puzzled by Idealizations and Understanding Their Functions." Philosophy of the Social Sciences 50 (3): 215-237.

Martin, Stephen. 2010. Industrial Organization in Context. Oxford: Oxford University Press.

McMullin, Ernan. 1985. "Galilean Idealization." Studies in History and Philosophy of Science Part A 16 (3): 247-273.

Musgrave, Alan. 1981. "'Unreal Assumptions' in Economic Theory: The Ftwist Untwisted." Kyklos 34:377-387.

Niiniluoto, Ilkka. 2002. "Truthlikeness and Economic Theory." In Fact and Fiction in Economics, edited by Uskali Mäki, 214-228. Cambridge, UK: Cambridge University Press.

Niiniluoto, Ilkka. 2012. "The Verisimilitude of Economic Models." In Economics for Real: Uskali Mäki and the place of truth in economics, edited by Aki Lehtinen, Jaakko Kuorikoski, and Petri Ylikoski, 65-80. London: Routledge.

Niiniluoto, Ilkka. 2018. "Explanation by Idealized Theories." Kairos 20 (1): 43-63.

Nowak, Leszek. 1980. The Structure of Idealization: Towards a Systematic Interpretation of the Marxian Idea of Science. Dordrecht: Reidel.

Popper, Karl R. 1963. Conjectures and Refutations: the Growth of Scientific Knowledge. London: Routledge / Kegan Paul. 
Potochnik, Angela. 2017. Idealization and the Aims of Science. Chicago: University of Chicago Press.

Reiss, Julian. 2012. "Idealization and The Aims of Economics: Three Cheers for Instrumentalism." Economics \& Philosophy 28 (3): 363-383.

Rice, Collin. 2019. "Models Don't Decompose That Way: A Holistic View of Idealized Models." British Journal for the Philosophy of Science 70 (1): 179-208.

Rodrik, Dani. 2015. Economics Rules: The Rights and Wrongs of The Dismal Science. New York: W. W. Norton.

Romer, David. 2019. Advanced Macroeconomics. 5th ed. First edition: 1996. New York: McGraw-Hill.

Shelegia, Sandro, and Chris Wilson. 2021. "A Generalized Model of Advertised Sales." American Economic Journal: Microeconomics 13 (1): 195223.

Shy, Oz. 1995. Industrial Organization: Theory and Applications. Cambridge, MA: MIT Press.

Singh, Nirvikar, and Xavier Vives. 1984. "Price and Quantity Competition in a Differentiated Duopoly." Rand Journal of Economics, 546-554.

Sugden, Robert. 2000. "Credible Worlds: The Status of Theoretical Models in Economics." Journal of Economic Methodology 7 (1): 1-31.

Sugden, Robert. 2009. "Credible Worlds, Capacities and Mechanisms." Erkenntnis 70 (1): 3-27.

Varian, Hal R. 1980. "A Model of Sales." American Economic Review 70 (4): 651-659.

Varian, Hal R. 1992. Microeconomic Analysis. 3rd ed. First edition: 1978. New York: Norton.

Vega-Redondo, Fernando. 2003. Economics and the Theory of Games. Cambridge, UK: Cambridge University Press.

Veit, Walter. 2019. "Model Pluralism." Philosophy of the Social Sciences 50 (2): 91-114.

Weisberg, Michael. 2007. "Three Kinds of Idealization." Journal of Philosophy 104 (12): 639-659.

Weisberg, Michael. 2013. Simulation and Similarity: Using Models to Understand the World. New York: Oxford University Press.

Werden, Gregory J., Luke M. Froeb, and David T. Scheffman. 2004. "A Daubert Discipline for Merger Simulation." Antitrust 18:89-95. 
Wimsatt, William. 2007. Re-engineering Philosophy for Limited Beings: Piecewise Approximations to Reality. Cambridge, MA: Harvard University Press.

Authors' biographies Edoardo Peruzzi is a $\mathrm{PhD}$ candidate in Economics at the Department of Economics and Statistics, University of Siena (Italy). His research interests lie at the intersection between economic methodology, formal epistemology and general philosophy of science. His current projects concern idealizations, scientific progress and realism (mainly in economics and social sciences) and the role of scientific experts, especially regarding the use of economic models by economics expert witnesses in the courtrooms.

Gustavo Cevolani is Associate Professor of Logic and Philosophy of Science at the IMT School for Advanced Studies Lucca (Italy). His research interests are mainly in general philosophy of science and formal epistemology, with a focus on rational decisions, the analysis of scientific and ordinary reasoning, the notion of cognitive progress, and on methodological issues in the social and behavioral sciences. 